\title{
Construction of China's Tea Futures Market From the Perspective of Optimizing Business Model
}

\author{
Yajun Shen* \\ Shandong Technology and Business University, Yantai City, Shandong Province, China \\ ${ }^{*}$ Corresponding author. Email: syj995@163.com
}

\begin{abstract}
The cultivation and processing of tea in China are generally carried out in a decentralized manner. There are many tea brands, great quality differences and price fluctuations, which lead to the decline of China's tea competitive advantage in the international market in recent years. Based on the ideas of bulk agricultural products futures, this paper puts forward some suggestions and methods to develop China's tea futures contract and establish China's tea futures market, hoping to provide reference for changing the business model of Chinese tea planting, processing and sales, and improving the international competitiveness of Chinese tea.
\end{abstract}

Keywords: Tea futures, Business model, Order, Insurance.

\section{INTRODUCTION}

China's tea production capacity is generally excessive. In the domestic market, the confusion of pricing does not play a strong role in guiding consumers, showing the characteristics of a buyer's market where supply exceeds demand; in the international market, China's tea has no pricing power and the export growth is insufficient, which leads to the saturation of the overall demand of China's tea market and the prominent contradiction of business model. Therefore, the establishment of "variety + geographical certification of origin + technical indicators + brand" of Chin's tea futures trading varieties and the construction of China's tea futures market are of positive significance to the formation of relevant tea varieties price mechanism, the expansion and strength of Chinese tea enterprises and even the formulation of government industrial policies.

\section{THE PRESENT SITUATION OF CHINESE TEA MARKET AT HOME AND ABROAD AND THE STRUCTURE CONTRADICTION OF BUSINESS MODEL}

\subsection{Current Situation of Domestic Tea Market in China}

China has thousands of years of tea planting and consumption history, and it is also a big tea export country. In 2019, China's tea output ranks first in the world with 2.43 million tons of tea, most of which are sold in China. China's consumers generally consume more than 2 million tons of tea annually through direct purchase from producing areas, exclusive stores, wholesale markets, supermarkets, online shopping, shopping malls and other channels, but the per capital consumption is not high. In 2019, China has a tea plantation area of more than 40 million mu, but most of the tea plantations take the family as the production unit, with low labor efficiency. Manual workshop production leads to low standardization of tea products, mixed brands, disordered pricing, and weak guidance for residents' tea consumption.

\subsection{Current Situation of China's Tea International Market}

In terms of export, according to the data of China Customs statistical yearbook and China's agricultural trade development report over the years, the international terms of trade of Chinese tea continued to deteriorate from 1995 to 2003. The trade competitiveness index of China's tea decreased from 2.09 in 1995 to 0.6 in 2004, and now it has risen to about 0.99. In 2000, there was a big gap in quality and sanitation between the export tea of numerous small tea processing enterprises in China and the international market, and the quality was uneven. The QS standard of tea enterprises was not strictly implemented, and the health and safety control was not in place. At the same 
time, disordered competition, and vicious competition among Chinese tea enterprises and tea merchants also caused serious price suppression. This phenomenon has greatly weakened the competitiveness of China's tea international trade. From 2004 to 2019, China's tea trade competitiveness index tends to rise, and the international terms of trade of tea will gradually improve. Through closing, stopping, merging, transferring and strengthening QS standardization measures for small processing enterprises in China, the quality and safety of tea have been significantly improved, and the level and efficiency of processing technology have been gradually improved. In 2015, China's tea export volume was less than that of Sri Lanka, ranking the second in the world; in 2016, the export value of tea was 1.48 billion US dollars, with an export volume of 329000 tons, ranking the third in the world.

\subsection{Structural Contradiction of Business Model in China's Tea Market}

China's tea is mainly distributed and processed by small farmers, which can not compare with the mechanized planting efficiency of Sri Lanka and other countries. Most tea exporters are small and medium-sized enterprises, mostly in the form of bulk raw materials. The structural contradiction of business model is prominent, and the brand effect is weak, resulting in the weak competitiveness of China's tea export.

At present, Chinese tea is mainly produced and processed in traditional way, and the level of industrial technology is not high. The popularization rate of improved tea varieties is low, and the average yield per unit area of tea is only $61 \%$ of that in the world. China's tea planting, processing, export industry chain and geographic information, quality and safety, standardization and other links of organic integration, mutual promotion and benefit complementary mechanism is not complete, and the structural contradiction of business model is prominent. Through the organic integration of tea planting, processing, circulation, consumption and other industrial chain elements, the annual output value of a British company is equivalent to $70 \%$ of the annual output value of China's national tea industry.

On the one hand, China's tea processing plants are generally backward in technology, outdated equipment, dilapidated workshops, poor sanitation, and unstable tea quality. Most of the tea processing plants lack of brand awareness, or mixed brand, pricing confusion, the guiding role of consumers is not strong, tea consumption growth is lower than the growth of tea production capacity. In addition, China's tea has no pricing power in the world, and its export is seriously insufficient. China is a big tea country but not a powerful country. At present, the overall demand of China's tea market tends to be saturated.

On the other hand, China's tea merchants have no large-scale planting base, so they can't plant large-scale mechanization; however, most of the tea farmers with scattered planting adopt the original sales mode such as self-produced and self-sale, which seriously hinders the resource allocation and business model innovation. Some centralized and contiguous tea production and operation areas should be managed by one company, but they are managed by small farmers in a decentralized way, which leads to serious tax evasion and tax evasion. On the surface, the number of comprehensive output value of tea is very large, but the government tax revenue is very small, which limits the implementation of relevant industrial, economic and financial policies of the government, resulting in waste or even failure, dislocation or vacancy of government public resources allocation, which further limits the basic functions of improving the formation mechanism of China's tea price, forming the capital market and providing direct financing by relevant institutions.

\section{THE VALUE OF FUTURES TRADING AND ITS REFERENCE TO THE ESTABLISHMENT OF TEA FUTURES MARKET}

In addition to providing farmers, middlemen, processing enterprises and final consumers with the price discovery function of related products, the futures market of agricultural products provides hedging tools for them to avoid the risk of market price fluctuation and performance risk, and provides a place to improve the market liquidity of related agricultural products. Futures market and futures trading provide a platform for banks, insurance companies and other institutions to develop products, serve agricultural production and establish a multilevel capital market, and also provide help for a government to formulate industrial policies.

\subsection{The Role of Tea Futures Market and Futures Trading on Tea Farmers, Middlemen and Tea Processing Plants}

First of all, tea farmers, middlemen and tea processing factories can use the price discovery function of futures market to guide their planting, trading and processing. Before planting, tea farmers can determine the varieties and yield according to the land conditions and climate of that year, combined with tea futures, spot market prices and price information. Tea processing factories and middlemen should not only refer to the price information of tea spot market over the years, but also determine the demand according to the relevant prices of tea futures, which will greatly reduce the price fluctuation of related tea varieties in the future. In the 
spot market, tea farmers can also use the price information of futures market as a reference to choose the right time to sell.

Secondly, tea growers, processing plants and middlemen can enter the futures market directly as independent entities to hedge, or several small tea farmers can form cooperative organizations to hedge indirectly. Tea farmers, processing plants and middlemen, as well as tea cooperative organizations, all hope to lock the price of tea at a certain level. They can choose to sell or buy short the corresponding tea varieties contracts that are equal to their own planting or demand. From the perspective of tea farmers, if the spot price of tea is lower than the original futures contract price, tea farmers or cooperatives can sell agricultural products according to the execution price when selling in spot. At this time, the transaction mode of physical delivery can avoid the risk of price falling in the spot market; if the spot price of tea is higher than the executive price of tea futures contract, the tea farmer or cooperative can sell the agricultural products according to the execution price Selling tea at current price and buying equal quantity of tea futures contract in futures market for closing position hedging. In addition, cooperative organizations (such as cooperatives) sell tea products in the form of highest selling price contract, lowest selling price contract, forward delivery contract and fixed basis contract, and indirectly enter the futures market to hedge and avoid risks, which can reduce operating costs, avoid the risk of tea price fluctuation, and improve the competitiveness and viability of tea farmers, processing plants and middlemen power.

\subsection{Banks, Insurance Companies and Other Institutions Use the Tea Futures Market and Futures Trading to Develop Products, Serve Tea Production and Establish a Multilevel Capital Market}

Futures market is closely related to bank credit business. Tea farmers, traders, processing enterprises and agents can obtain short-term loans from banks with written credit certificates such as tea futures bills (i.e. forward sales contracts or futures and option contracts for future purchase of tea) as collateral, which can promote the development of bank credit business and boost tea circulation trade. When American banks make loans to farmers or enterprises, they usually consider whether to participate in the futures market hedging, that is to say, hedging in the futures market is an important examination index of loan granting, and then make corresponding loans according to the hedging period and scale of farmers or enterprises. This kind of loan based on the hedging of agricultural futures bills can not only solve the problem of insufficient funds of farmers or enterprises, but also enhance the quality of loans, which is conducive to reducing the credit risk of banks and greatly reducing the market risk of agricultural products.

In addition, banks can also use the futures market to develop hedging loans, standard warehouse receipt pledge loans and financial products with tea futures and options as the subject matter of loans or derivative financial products. Tea farmers buy tea income insurance, when faced with income loss; they can apply for compensation from insurance companies and effectively ensure the stability of income, while insurance companies can avoid the claim risk by directly or indirectly buying and selling relevant tea futures contracts in the futures market. Banks, insurance companies and other institutions use tea futures market and futures trading to serve agricultural production, and promote the establishment of multilevel capital market through diversified product development.

\subsection{The Government Uses the Tea Futures Market and Futures Trading as an Important Reference for Formulating Price, Credit and Industrial Policies}

From the perspective of the developed countries (such as the United States) where the futures market and futures trading are relatively mature, the trading varieties in the futures market gradually develop from primary products such as meat, milk, livestock products to high-end products such as commodity price index Through the "futures+credit" and "futures+insurance" modes, the Futures (or options) market and agricultural subsidy policies are combined the transformation from direct financial subsidy to market-oriented subsidy mechanism effectively solves the problem of excessive government financial subsidy burden. By providing low interest loans to farmers who purchase futures and options, farmers' income is effectively guaranteed. By purchasing agricultural futures contracts through private sales option premium, private sector option risk premium and public option contract, and by transforming inefficient financial subsidy policy into a market-oriented adjustment mechanism, farmers' income is effectively guaranteed. Because of the dependence of producers on government support, many agricultural products futures have become the standard of international market price formation mechanism.

\section{THE EXPLORATION OF TEA FUTURES IN CHINA'S CURRENT TEA TRADING MARKET}

\subsection{Tea Exchange Based on Spot Wholesale, Retail and Auction}

In recent years, some tea exchanges have been established in China's major tea producing areas, such as Wuyishan National tea auction and trading center, 
Hangzhou China International tea auction market trading service center, and national comprehensive tea trade center in Anxi County, Fujian Province. Most of the trading modes of these tea exchanges are the same, that is, the trading varieties are limited, and the wholesale mode is mainly adopted, and most of them focus on famous and high-end tea. Although there are auction transactions, it is only a guide to the spot market price, not to the futures trading.

\subsection{Internet plus Tea Exchange Mode}

Mengding tea exchange in Sichuan province integrates the resources of the industry's chain of tea production, supply and marketing in the region. Based on the tea spot exchange, the $\mathrm{B} 2 \mathrm{C}$ e-commerce tea platform is established by using the Internet plus tea mode. The platform introduces tea growers, tea merchants, tea enterprises and tea art, provides the organization test certificate of physical and chemical indicators, and establishes accurate product trace-ability, anti-counterfeiting, insurance claim and other mechanisms covering the whole industry chain of tea production and circulation, so as to ensure product quality and reduce operating costs, forming a complete trading system. At the same time, it has established tea finance, tea storage and other financial services. For the tea traded in the exchange, the classification standard system, classification evaluation and classification pricing system shall be established. This exchange mode has made a positive and meaningful exploration for tea futures trading in terms of product classification, free bidding and the participation of financial institutions.

\section{SUGGESTIONS ON THE CONSTRUCTION OF CHINA'S TEA FUTURES MARKET}

In the global futures and options report released by the American futures association in 2014, the total turnover of China's agricultural futures market is large and the total volume is the largest in the world. Although the volume of agricultural futures in China is large, $30 \%$ of the total futures contracts in 2015 are agricultural products futures, and the total number of contracts concluded is 1.075 billion. However, the utilization of agricultural products futures by farmers in China is very low, only about $6.9 \%$. This has brought great growth space for farmers to use agricultural products futures to guide planting, processing and sales, and also provided opportunities for the establishment of tea futures market.

\subsection{Development and Design of Tea Futures Contract}

Different from corn, soybean and other bulk agricultural products, tea will form a multivariate contract due to differences in origin, natural conditions, picking season, processing technology and varieties. On the one hand, it increases the difficulty of classification of tea futures contracts, on the other hand, it also provides rich investment opportunities for market participants. Therefore, the tea futures contract should be developed and designed with the idea of "variety+ geographical certification of origin+technical indicators+brand" under the premise of fully considering the participants of market contract, market liquidity and integrating with the international market. The main terms of the tea futures contract, such as trading unit, contract month, minimum price change, execution price and method of execution, shall be formulated by the exchange.

\subsection{Trading Subject and Mode of Tea Futures Contract}

\subsubsection{Tea Farmers+Tea Futures Market}

Tea farmers with large planting area and single variety can directly open an account in the exchange, sell tea futures contracts, lock the price and realize hedging. That is, tea farmers arrange their own production according to the contract order standard. If the spot price is higher than the futures execution price at harvest, the tea farmers can sell tea according to the market in the spot market, and at the same time, buy the futures contract of the same variety in the futures market for hedging. If the spot price at harvest is lower than the previous contract price, in order to avoid the risk of decline in spot market price, the tea futures contract can be hedged to ensure the income.

\subsubsection{Professional Cooperatives+Tea Futures Market}

Scattered small tea farmers form professional cooperatives by contract to participate in the tea futures market. At this time, the direct participants become tea farmers' professional cooperatives, and the hedging method is the same as above. But it will indirectly promote the popularization of improved varieties and the improvement of planting and processing technology.

\subsubsection{Consortium+Tea Futures Market}

Tea processing enterprises or small tea producers and marketing enterprises were established in the form of tea processing and marketing. At this time, the direct participants are tea processing enterprises or large tea merchants. They make purchasing plans according to the futures price information, achieve the goal of reducing costs and maximizing profits, and realize the industrial guidance and financial assistance of "order+futures" and "insurance+futures". Through the introduction of fund companies, insurance companies and other institutions, investment institutions and insurance markets, we can 
design more financial products that are conducive to the development of the industry.

\section{CONCLUSION}

The development of tea futures contract and the establishment of tea futures market based on the idea of "variety+geographical certification of origin+technical indicators+brand" is conducive to the intensive and large-scale operation and business model transformation of Chinese tea cultivation, the establishment of improved varieties cultivation, cultivation and variety standardization, the improvement of processing technology, the enhancement of domestic and international competitiveness of tea industry, and the establishment of investment market and tea futures market The participation of insurance market and the development of derivative products will help to solve the financing problems of tea enterprises and tea farmers. In line with the WTO rules, it provides a new way for the government to support and subsidize related industries by means of marketization and to optimize the business model.

\section{REFERENCES}

[1] LAN Haocheng. Enlightenment of American agricultural futures market on China's tea development[J]. Rural economy, 2016 (4), PP.125-129.

[2] Wang Yanqing. Development of foreign agricultural futures market [J].World agriculture, 2017 (5), PP.4-12.

[3] Fan yongjuan.Research on improving the international competitiveness of China's tea trade with the United States [J]. Price monthly, 2017 (11), PP. 47-50.

[4] $\mathrm{Xu}$ Yongmei. Empirical Study on the change of China's tea terms of trade and its influencing factors [J]. Tea, 2017 (4), PP. 213-218.

[5] Wei Zhiyong, Zhou Jie, Wu Yiyuan, Zheng Yali, Lin Chang. Analysis on the construction and development of Tieguanyin tea economic circle in Southern Fujian[J]. Taiwan agricultural exploration, 2018 (01), PP. 64-69. 